\title{
A agricultura nas negociações multilaterais da Rodada Doha e suas implicações para o Brasil
}

\author{
Tatiana S. Fukuda Rodrigues
}

Nilson M. de Paula ${ }^{2}$

\begin{abstract}
Resumo: A análise desenvolvida neste artigo trata da evolução do comércio mundial, com ênfase nas negociações multilaterais, desde a criação do GATT em 1948, até a presente Rodada Doha de negociações da OMC. Para tanto, destaca-se o papel das instituições na construção de um ambiente mais propício para o livre comércio, particularmente na agricultura. Afinal este tem sido um setor crucial, não apenas para o avanço das negociações em curso, mas também para as relações comerciais do Brasil. Adicionalmente, a agricultura tem sido um dos setores mais protegidos no comércio mundial, tendo estado fora da regulamentação do GATT até a Rodada Uruguai, quando foi aprovado o acordo sobre agricultura, implementado a partir de 1995. Tendo em vista o curto alcance de seus resultados em termos de diminuição de subsídios e tarifas à agricultura, este setor de atividades continua no centro do impasse que tem marcado a Rodada Doha. É em grande parte devido a isso que a grande expectativa de uma maior liberalização do comércio deu lugar a uma incerteza generalizada quanto a um avanço satisfatório nas negociações.
\end{abstract}

Palavras-chave: comércio agrícola; Rodada Doha; agricultura brasileira.

\section{Agriculture in the multilateral negotiations of the Doha Round and their implications for Brazil}

\begin{abstract}
This article aims to analyse the evolution of world trade, with emphasis on the multilateral negotiations, since GATT was created in 1948, through the current Doha round of WTO. The role of institutions in building a favourable environment for free trade, particularly in agriculture, is stressed. After all, not only has the farming sector been crucial for the negotiations to succeed, but also for the trade relations of many developing countries, including Brazil. Besides, agriculture has been one of the most protected sectors in world trade and as such

\footnotetext{
1 Economista pela Universidade Federal do Paraná.

2 Professor Doutor do Departamento de Economia e do Programa de Pós-Graduação em Desenvolvimento Econômico da Universidade Federal do Paraná. E-mail: nilson@ufpr.br.
} 
RODRIGUES, T. \& PAULA, N. A agricultura nas negociações multilaterais...

out of reach of GATT regulation until the conclusion of the Uruguay Round. Given that subsidies, tariffs and other mechanisms of protection still prevail in agricultural policies of some countries, this sector still remains as the deadlock of the unfinished Doha Round. That is why the previous expectations of progresses in trade liberalization have given place to a widespread uncertainty as the negotiations carry on.

Key-words: agricultural trade; Doha Round; Brazilian agriculture

JEL: F13

\section{Introdução}

O comércio internacional tem passado por grandes mudanças desde a Segunda Guerra Mundial, entre as quais se destacam a crescente importância do padrão de comércio intraindustrial e uma maior exposição comercial dos países. Neste contexto, o GATT (Acordo Geral sobre Comércio e Tarifas), e sua sucessora, a OMC (Organização Mundial do Comércio), tiveram um papel essencial para reduzir o nível de protecionismo herdado do período entre guerras e para promover um ambiente multilateral visando proporcionar ganhos a todos os países envolvidos no comércio mundial. Assim, embora as rodadas de negociação realizadas até o início dos anos 70 tenham negligenciado a agricultura, este setor se converteu no ponto de maior conflito, especialmente entre os países desenvolvidos. Assim é que o objetivo desta análise é demonstrar as negociações multilaterais agrícolas no âmbito daquelas organizações, com ênfase nas perspectivas que trazem para a economia brasileira.

Para tanto, em primeiro lugar, um referencial de análise é apresentado, no qual as principais teorias de comércio internacional são resgatadas. Além disso, atenção é dada à importância das instituições no funcionamento do comércio mundial, em que se torna importante o histórico das negociações multilaterais de comércio através das sucessivas rodadas. Em seguida destaque é dado à agricultura no contexto das negociações multilaterais. Verifica-se que os resultados mais relevantes no setor foram obtidos apenas na década de 90 , com o Acordo sobre a Agricultura da Rodada Uruguai. Desde então, o tema agrícola tem sido polêmico e fonte de diversos impasses no âmbito da OMC. A partir disso, são discutidos os impactos e as perspectivas das negociações multilaterais agrícolas para o Brasil, tendo em vista tanto o peso das exportações agrícolas na balança comercial brasileira, quanto o papel inibidor exercido pelas políticas comerciais protecionistas dos países desenvolvidos na competitividade do agronegócio do país. Por fim, são apresentadas considerações conclusivas da presente análise. 


\section{Referencial analítico para o mundo real do comércio}

Apesar das limitações do modelo ricardiano das vantagens comparativas para explicar a crescente complexidade do comércio desde o início do século $\mathrm{XX}$, seus princípios foram preservados em várias das formulações teóricas posteriores. Nesse sentido, o pressuposto do livre comércio associado à busca da eficiência é incorporado como uma condição da competição internacional, de acordo com a eficiência relativa e da distribuição pré-existente dos recursos produtivos entre os países. $\mathrm{O}$ desdobramento de maior relevância nessa evolução é observado no modelo de proporção de fatores, também conhecido como modelo HO-S.

Desde meados dos anos de 1980, a onda liberalizante que se propagou em todas instâncias econômicas, se tornou referência para o entendimento e condução das decisões dos governos, dos fazedores de política e das instituições multilaterais. Todavia, no mundo real dos negócios de vários setores, destacadamente a agricultura, tal orientação esbarrou em dificuldades situadas em poderosos lobbies domésticos sustentados por setores produtivos cuja competitividade não suportam a emergente concorrência internacional.

Atualmente já se admite que as vantagens comparativas são arbitrárias, baseadas nas mudanças tecnológicas e nos movimentos dos fatores, dependendo das estratégias das empresas e das políticas dos países, e não somente de vantagens estáticas baseadas na disponibilidade de recursos. Nesse sentido, argumentos sustentando que vantagens competitivas podem ser criadas por políticas setoriais de incentivo e proteção (Gilpin 2002) vêm se opondo àqueles adeptos do ideário liberal, para quem estratégias protecionistas são fontes de ineficiência e distorção no comércio mundial. No caso específico da agricultura, a intensificação das relações comerciais passou, a partir de meados dos anos 60 , a colidir mais significativamente com as estratégias dos governos nacionais visando dar estabilidade de oferta nos mercados domésticos e ao mesmo tempo manter poder de compra aos produtores. As particularidades de um setor, essencialmente tomador de preços e sujeito a condições naturais e erráticas de produção, se tornaram mais explícitas e alimentaram demandas recorrentes por medidas de compensação às instabilidades daí oriundas, na forma de políticas de proteção e estímulo.

Ao longo do período pós II guerra, a expansão do comércio foi essencialmente marcada por mudanças na divisão internacional do trabalho, traduzidas pelo surgimento de um novo quadro competitivo nos mais diversos segmentos produtivos. Um generalizado processo de industrialização, em muitos casos via substituição de importações, fez com que 
RODRIGUES, T. \& PAULA, N. A agricultura nas negociações multilaterais...

muitos países se afastassem da posição agroexportadora de suas economias. Ao mesmo tempo, a revolução verde transformou a agricultura de muitos países, tornando-os fortes competidores nos mercados das principais commodities agrícolas, especialmente aquelas vinculadas ao complexo protéico. Associado a isso, os mercados mundiais passam a refletir mais claramente as estratégias nacionais de política agrícola voltadas para a garantia de abastecimento alimentar e/ou geração de excedentes exportáveis. Como resultado, o padrão de comércio predominante nas trocas internacionais, passa a incorporar gradativamente transações distintas daquelas típicas do padrão de comércio Norte-Sul. Mais ainda, os preços passaram a oscilar mais fortemente enquanto aumentavam as dificuldades dos países arquitetarem um arranjo multilateral para as transações comerciais mundiais. A expectativa de cooperação entre países exportadores deu lugar a um ambiente de guerra comercial, em que acordos bilaterais se tornaram mais comuns (Tubiana 1989). De modo é que o princípio do livre comércio acoplado às vantagens comparativas, permeando a maior parte das análises, passou a ser desafiado pela proliferação de estratégias protecionistas sob diversos arranjos institucionais. Ao mesmo tempo, uma ampla fragmentação dos mercados e uma concorrência mais acirrada entre países exportadores adicionaram significativas incertezas nas negociações conduzidas pelo GATT/OMC que visavam uma multilateralização do comércio mundial.

Portanto, o fato das estratégias baseadas no livre comércio não serem um fenômeno generalizado resulta na realidade de ações voltadas tanto para a proteção de interesses locais quanto para construção de capacidades competitivas em setores específicos (Chang 2002). Dessa forma, as estruturas institucionais condutoras de políticas comerciais são na realidade ingredientes estruturais do comércio e não instâncias de desajuste ou de desequilíbrio a serem eliminadas pela hegemonia do livre mercado combinada com o enfraquecimento do Estado.

\section{A evolução das negociações multilaterais}

O ponto de partida da trajetória do arranjo institucional visando à promoção de regras multilaterais e de um comércio mundial mais livre está situado na criação do GATT, em 1948, após a conferência de Bretton Woods, realizada com o propósito de construir uma nova ordem econômica internacional. Todavia, essa instância foi uma solução provisória diante da tentativa frustrada de criação da Organização Internacional do Comércio (OIC), que já constava na pauta de negociações, tendo em vista o quadro de excessivo protecionismo predominante no período entre guerras (Trebilcock \& Howse 1995). 
Em 1950 foi selado o fracasso da criação da OIC a partir da desistência do presidente norte-americano em solicitar sua aprovação ao congresso, tendo em vista a oposição da opinião pública e dos empresários norteamericanos cujos interesses seriam afetados pela existência de um organismo regulador internacional. Além disso, o projeto de construção de um ambiente multilateral de comércio entrou em direto confronto com a proposta dos países europeus, que desejavam manter sua capacidade de intervenção na política comercial, com objetivo de reconstruir sua economia. Assim, o GATT passou a funcionar na prática e se consolidou como a organização internacional multilateral reguladora do comércio de fato. No entanto, essa organização padeceu da falta de personalidade jurídica e de capacidade de articular todos os seus signatários em torno de uma agenda liberalizante para o comércio mundial (Delgado 2000).

Durante o período de vigência do GATT ocorreram sete rodadas de negociações, além da conferência de sua instalação em Genebra, sendo Annecy (1949), Torquay (1950), Genebra (1956), Dillon (1960-1), Kennedy (1962-7), Tóquio (1973-9) e Uruguai (1986-94). Segundo McDonald (1998), a estratégia do GATT de funcionar através de rodadas de negociação tinha como objetivo um acordo dos países em torno de reduções mútuas de proteção. Quando um acordo era selado, beneficiava principalmente os países proponentes, mas devia ser estendido a todos os outros países do GATT, evitando acordos bilaterais e envolvendo todos os participantes, mesmo aqueles com menor poder de barganha.

As primeiras rodadas multilaterais abordaram principalmente tarifas sobre produtos manufaturados. A partir da Rodada Kennedy, as negociações passaram a envolver também as proteções não-tarifárias e a agricultura, sendo que na última rodada do GATT, já na década de 1990 foram incluídos serviços, propriedade intelectual e regras de origem (Hoeckman \& Kostecki 1995). Além do avanço na abrangência de temas tratados nas negociações, o número de países signatários aumentou significativamente desde a criação da organização, passando de 23 países integrantes da primeira rodada, para 123 na Rodada Uruguai. Conseqüentemente o montante de comércio coberto pelas negociações aumentou de US\$ 10 bi para US\$ 500 bi entre as duas rodadas (McDonald 1998). No mesmo sentido, segundo dados da OMC (2005b), estima-se que, durante os 50 anos que se seguiram à criação do GATT, as exportações aumentaram 6\% a.a. em média, enquanto o volume total de comércio chegou em 1997 a ser 14 vezes maior que em 1950. Este crescimento decorreu de diversos fatores, como o crescimento da economia mundial, o aumento do PIB dos países e a maior participação de novos países no comércio mundial. Avaliação semelhante pode ser observada em Hirst \& Thompson (1996), ao 
RODRIGUES, T. \& PAULA, N. A agricultura nas negociações multilaterais...

indicarem que entre 1960 e 1991, o crescimento das exportações mundiais foi muito maior que o do produto.

Embora essa trajetória esteja fortemente associada ao dinamismo da economia mundial após a segunda guerra, o GATT teve um papel importante no maior fluxo de comércio por reduzir o nível médio de barreiras tarifárias. Deve ser reconhecido, todavia, que após meados dos anos de 1970, o maior obstáculo para o GATT passou a ser o chamado novo protecionismo, caracterizado por barreiras não tarifárias. Embora associadas principalmente ao comércio de produtos industriais, tais práticas não convencionais, ou não tarifárias, de proteção tiveram ampla aplicação nos produtos agropecuários, entre as quais podem ser destacadas as políticas compensatórias de transferência de renda, subsídios, cotas, barreiras fito-sanitárias, etc. De uma maneira geral, a agricultura, especialmente dos países desenvolvidos, a partir de meados dos anos de 1950, deixa de ser alvo apenas de restrições tarifárias e passa a se beneficiar de outros mecanismos de proteção.

Após a Rodada Tóquio, uma nova onda de protecionismo marcou as relações internacionais, decorrentes, entre outros eventos, dos choques do petróleo e do acirramento da concorrência internacional tanto no comércio de produtos industriais quanto agrícolas. Segundo Trebilcock \& Howse (1995), este cenário fez com que os países desenvolvidos recorressem às barreiras não-tarifárias para proteger seu comércio. Por sua vez a Rodada Uruguai, mesmo após uma previsão inicial de duração de quatro anos, acabou se estendendo por oito anos e se tornando a mais difícil e complexa rodada de negociações. Isso se deveu tanto à amplitude da agenda em pauta, em vista da complexa rede de proteção criada ao longo dos trinta anos anteriores, quanto à incapacidade dos governos em removê-la.

Mesmo num cenário de dificuldades, a última rodada do GATT foi capaz de promover a maior reforma do sistema de comércio mundial e trouxe grandes avanços principalmente nos setores da agricultura, de produtos têxteis, de serviços e de direitos de propriedade intelectual. Embora não tenha sido contemplada nas negociações anteriores, a agricultura esteve no centro da Rodada Uruguai. Como resultado, em 1995 entrou em vigor o Acordo sobre Agricultura da Rodada Uruguai (AARU), determinando regras para a redução de subsídios domésticos, a transformação de barreiras não-tarifárias em tarifas, a redução de tarifas, e garantia de acesso mínimo de produtos altamente protegidos aos mercados. Esta última consiste numa percentagem mínima do consumo doméstico a ser atendida por produtos importados. O AARU resultou de um acordo bilateral entre Estados Unidos e União Européia, chamado Acordo de Blair House, formulado com o objetivo de superar os impasses no grupo de negociações agrícolas e, apesar de representar grande 
avanço, ainda mantinha várias exceções, permitindo o protecionismo na agricultura (Araújo et al. 2005: 39).

Um dos resultados mais importantes da última rodada do GATT foi o da criação da Organização Mundial do Comércio (OMC), não mais um acordo provisório e sim uma organização formal, com poder para estabelecer regras disciplinares para o comércio. Esta nova organização, além de regular o comércio multilateral de bens e serviços e os direitos de propriedade intelectual, funciona como um tribunal internacional para resolução de impasses entre países. O Órgão de Solução de Controvérsias, formado pelos membros da OMC, é responsável por resolver impasses e acompanhar o cumprimento de recomendações, além de ter o poder de estabelecer sanções aos países excessivamente protecionistas como punição, caso seja decidido que houve descumprimento de regras.

Outro aspecto importante é que todas as decisões no âmbito da OMC são tomadas por consenso, diferente de outras organizações internacionais, onde o poder é delegado a um conselho de diretores ou similar. Desta maneira, as decisões são mais facilmente aceitas, mas há uma grande dificuldade para se atingir consenso entre seus 149 membros. Desde sua criação, em 2000, ocorreram negociações multilaterais visando à instalação da Rodada Doha ${ }^{3}$, cuja ambiciosa agenda, envolvia 21 temas amplos e complexos e uma participação mais ativa de países que estiveram ausentes nas rodadas anteriores. O objetivo do que ficou conhecido como Agenda Doha de Desenvolvimento foi estabelecer modalidades que garantam "reduções substanciais no apoio interno distorcivo ao comércio, incremento no acesso a mercados, eliminação progressiva de todas as formas de subsídios à exportação e tratamento especial e diferenciado operacional que leve em conta a segurança alimentar e de meios de vida e as necessidades de desenvolvimento rural” (G-20 2004).

Em particular, os países em desenvolvimento exigiram logo no início da rodada a Declaração sobre Questões de Implementação, para reivindicar o direito de tratamento especial assegurado nos acordos da Rodada Uruguai e não respeitados pelos países desenvolvidos (BRASIL, SECEX 2001).

Até início de 2006, haviam ocorrido três conferências como parte da agenda da presente rodada: Cancun em 2003, Genebra em 2004 e Hong Kong em 2005. Ao longo dessas conferências ganhou destaque a coalizão do G-20, na qual o Brasil tem posição de liderança, pois luta pela liberalização do comércio agrícola nos países desenvolvidos e defende condições especiais aos países em desenvolvimento.

3 Iniciada oficialmente em 2001 com a IV Conferência Ministerial da OMC, no Qatar. 
RODRIGUES, T. \& PAULA, N. A agricultura nas negociações multilaterais...

Apesar do nível de ambição inicial, já em 2003, na V Conferência Ministerial da OMC em Cancun, os países-membros mostraram grandes dificuldades em atingir um consenso, o que levou à interrupção da conferência. A partir de então, a ambição das propostas de reformas apresentadas na rodada tem diminuído (Jank \& Jales 2003:2). Um dos temas mais sensíveis no ambiente das negociações é a agricultura, marcada pelos conflitos de interesses principalmente entre União Européia (posição defensiva no acesso a mercados), Estados Unidos (posição defensiva nos subsídios agrícolas) e países do G-20 (liberalização nos países desenvolvidos, mas proteção para aqueles em desenvolvimento). Por conta desses conflitos, avanços na eliminação de distorções na agricultura representam, uma vez mais, os principais desafios para conclusão da Rodada Doha.

Alguns impasses nas negociações da agricultura têm surgido a partir do receio de países menos competitivos, como os da União Européia, de serem expostos à concorrência com nações mais competitivas no agronegócio, como os integrantes do $\mathrm{G}-2 \mathrm{O}^{4}$. No entanto, um dado que deve acompanhar este argumento é a importância da agricultura para o desenvolvimento dos países de renda média integrantes daquele grupo. Em 2001, a agricultura correspondia em média a 50\% dos empregos nos países em desenvolvimento, enquanto que, em países ricos, correspondia à cerca de 7,3\% dos empregos (Acharya \& Daly 2004:13).

Em decorrência do cenário de dificuldades na obtenção de acordos, o prazo inicial para conclusão das negociações da Rodada Doha, que era janeiro de 2005, foi prorrogado para o final do ano de 2006. Mais recentemente, após o fracasso de uma reunião entre seis dos maiores membros da OMC, em Julho de 2006, com objetivo de avançar rumo à conclusão da rodada, o Diretor Geral Pascal Lamy anunciou a suspensão da Rodada. Uma das possíveis conseqüências desse frustrante desfecho é que os países alimentem estratégias de acordos bilaterais ou regionais como alternativa de comércio, promovendo assim um ambiente de comércio mais fragmentado e protegido.

\section{Agricultura nas negociações multilaterais}

A regulamentação do comércio agrícola começou efetivamente muito mais tarde do que em outros setores, devido às inúmeras exceções

4 Outro fator de instabilidade no cenário futuro do comércio multilateral é o fim do fast track nos EUA, em meados de 2007. A TPA (Autoridade para Promoção Comercial), resultou de uma autorização do Congresso ao presidente americano para negociar acordos comerciais durante cinco anos. Por isso, quanto mais a conclusão da Rodada Doha é retardada, maior é a chance de que o congresso americano possa limitar as ações da organização multilateral, a exemplo do que ocorreu quando da então criada OIC. 
resguardadas pelos acordos comerciais. Embora o GATT-1947 tenha sido aprovado com a intenção de regulamentar o comércio mundial, no que se refere à agricultura garantia exceções que permitiam a existência de barreiras ao comércio. Um exemplo foi o artigo do GATT instituído em 1955 que proibia subsídios à exportação, mas que tinha uma exceção para os produtos agrícolas. Outra exceção importante foi conquistada pelos EUA, também em 1955, com a suspensão de obrigações que lhe dava direitos de impor restrições quantitativas a produtos agrícolas. Desta maneira, a agricultura ficou à parte da regulamentação do comércio mundial estabelecida na época (Araújo et al. 2005:38).

Igualmente, menção deve ser feita ao relatório Haberler de 1958, elaborado a pedido dos membros do GATT, segundo o qual os países em desenvolvimento, entre os quais o Brasil, reconhecidamente enfrentavam dificuldades no comércio exterior devido à política de restrições praticada pelos países desenvolvidos. A partir disso, uma comissão formada especificamente para tratar dessa questão demonstrou que tais dificuldades estavam relacionadas à imposição de elevadas tarifas tanto a produtos industriais quanto agroindustriais tipicamente tropicais, tais como café, chá, cacau, açúcar, tabaco, etc. Se por um lado, as propostas de limitação de tais políticas foram aceitas pelos países membros do GATT, por outro isso não implicou submeter os vários setores protegidos às regras de livre comércio. Sendo assim, a execução de políticas tarifárias nocivas aos projetos de desenvolvimento de países em processo de industrialização já refletiam a existência de conflitos nas relações comerciais.

Apesar das avaliações resultantes da comissão liderada por Haberler, uma das primeiras manifestações a favor de uma liberalização agrícola geral foi a declaração ministerial da OCDE (Organização para Cooperação e Desenvolvimento Econômico) de 1987, que ressaltava a necessidade de inclusão mais efetiva do comércio agrícola ao sistema multilateral e de ajustes nas políticas domésticas a partir das negociações multilaterais (McDonald 1998). Foi então que, na Rodada Uruguai a diminuição das barreiras às exportações agrícolas se tornou o ítem mais visível das negociações. No entanto, sérias dificuldades emergiram, derivadas da pressão do forte lobby agrícola nos países desenvolvidos e do conflito entre Estados Unidos e União Européia. Mais ainda a agricultura não só teve papel de destaque na Rodada Uruguai, mas se revelou o determinante do sucesso ou fracasso da rodada.

O AARU (Acordo sobre Agricultura da Rodada Uruguai) marcou o fim das negociações sobre agricultura da rodada, após o longo período de oito anos, e representou um passo na direção de um mercado mais livre. No entanto, o resultado não correspondeu à ambição inicial de alguns países e ainda resguardou exceções a alguns tipos de proteção. Os 
RODRIGUES, T. \& PAULA, N. A agricultura nas negociações multilaterais...

principais elementos do AARU podem ser divididos em suporte doméstico, subsídios à exportação, barreiras não tarifárias, tarifas, e medidas sanitárias e fitossanitárias:

a) suporte doméstico - as políticas comerciais agrícolas foram enquadradas com base na sua aceitação pelos membros do GATT nas caixas verde, amarela ou azul. A caixa verde corresponde a políticas que, segundo os membros, não causam distorções ao comércio mundial e são permitidas; a caixa amarela contém políticas que devem ser diminuídas e que são proibidas caso excedam os limites de redução acordados; e a caixa azul é similar à caixa amarela, mas é composta apenas por políticas que limitam a produção. Para a agricultura não há caixa vermelha, que seriam proteções proibidas;

b) subsídios à exportação - os apoios governamentais às exportações deveriam ser reduzidos em relação ao total de gastos com subsídios e à quantidade de exportações beneficiadas, conforme quantidades mencionadas acima. Nos países desenvolvidos a redução seria feita num período de seis anos, já nos países em desenvolvimento este prazo era de dez anos;

c) barreiras não tarifárias - a regra geral é que todas estas barreiras deveriam ser eliminadas e convertidas em tarifas, que seriam adicionadas ao total de tarifas a serem reduzidas. No entanto, o acordo contemplava a possibilidade de um membro não converter a totalidade de suas barreiras. Neste caso ele deveria permitir um acesso mínimo de importações do produto em questão com baixa tarifação;

d) tarifas - a meta é a redução em 36\% das tarifas por cada membro, sendo necessária uma redução de pelo menos $15 \%$ em cada categoria de produto. Além disso, foi estabelecida uma tarifa máxima para cada produto, que não poderia ser ultrapassada ao final do período de implementação, de seis anos para os países desenvolvidos e de dez anos para aqueles em desenvolvimento ;

e) medidas sanitárias e fitossanitárias - elas funcionam como exceções ao livre comércio, em casos de proteção da saúde humana, animal ou vegetal e podem ser utilizadas com finalidades protecionistas. Para evitar que isso aconteça, o acordo determina a necessidade de haver comprovação científica antes da aplicação da medida e de ser elaborado um estudo de riscos relacionados à doença, resíduos, agrotóxicos ou aditivos alimentares que se pretende evitar. 
Uma das consequiências da implementação do AARU foi a presença de picos e escaladas tarifárias, decorrentes do processo de transformação de barreiras não-tarifárias em tarifas equivalentes. Conseqüentemente, as tarifas para agricultura de países desenvolvidos ainda são mais altas do que as tarifas para produtos industriais, sendo que a tarifa média de commodities, em 2001, variava de 50\% a 91\%. Mas mesmo com aumento das tarifas, o total de ajuda para o setor agrícola de países desenvolvidos caiu de 2,2\% do PIB em 86-88, para 1,3\% do PIB em 98-00 (Diakosavvas 2001). A utilização de subsídios à exportação também diminuiu devido ao acordo, embora a União Européia ainda seja o principal usuário deste tipo de proteção, correspondendo a 90\% dos subsídios à exportação entre 1995-97. A mais importante conquista da Rodada Uruguai foi trazer a agricultura para o centro das negociações e garantir que haja alguma reforma no setor, mesmo que alguns autores considerem que o progresso na redução de proteções à agricultura tenha sido limitado.

Conforme previsto em 2000 novas negociações agrícolas ocorreram na então iniciada Rodada Doha, renovando a oportunidade de aprofundar o processo de reforma e liberalização do comércio agrícola iniciado na Rodada Uruguai. Assim, um dos principais desafios da rodada foi o de definir um processo de diminuição das tarifas, ainda mantidos em altos níveis em alguns casos. Outro ponto a ser desenvolvido nas negociações diz respeito ao acesso a mercados, já que o processo de tarificação fez com que o nível de proteção das fronteiras ficasse mais transparente. No entanto, o que se observa nas negociações é uma grande dificuldade em atingir consenso entre os países membros no que se refere à agricultura.

Em 2002, numa estratégia destoante do espírito multilateral da rodada, os Estados Unidos aprovaram a Lei Agrícola mais protecionista de sua história, com previsão de dobrar subsídios a agricultores na próxima década. Por sua vez, a União Européia promoveu, em 2003, uma mini reforma na Política Agrícola Comum, incapaz de promover a redução esperada do protecionismo nesse setor. Enquanto isso, o grupo de países em desenvolvimento G-20 alcança maior representatividade e passa a ter papel ativo nas negociações, visando redução do protecionismo ao agronegócio nos países desenvolvidos e defendendo tratamento diferenciado aos países em desenvolvimento (Araújo et al. 2005:58).

A maior resistência aos acordos agrícolas vem de países da União Européia, EUA e Japão, justamente os que mais utilizam o poder do Estado para interferir no comércio agrícola. Esta resistência é causada por pressões internas de representantes do agronegócio nos governos e pela crescente concorrência no setor. Nos países da OCDE, a agricultura representa apenas $2 \%$ do PIB, enquanto nos países em desenvolvimento corresponde à cerca de 25\% (Acharya \& Daly 2004:13). Ao mesmo 
RODRIGUES, T. \& PAULA, N. A agricultura nas negociações multilaterais...

tempo em que, nos países da OCDE os subsídios correspondem em média a 30\% das receitas da agricultura, enquanto no Brasil este número representa apenas 3\% (Gráfico 1).

GRÁFICO 1. SUBSÍDIOS DE PAÍSES SELECIONADOS, COMO PERCENTAGEM DAS RECEITAS DA AGRICULTURA - MÉDIA 2002-2004

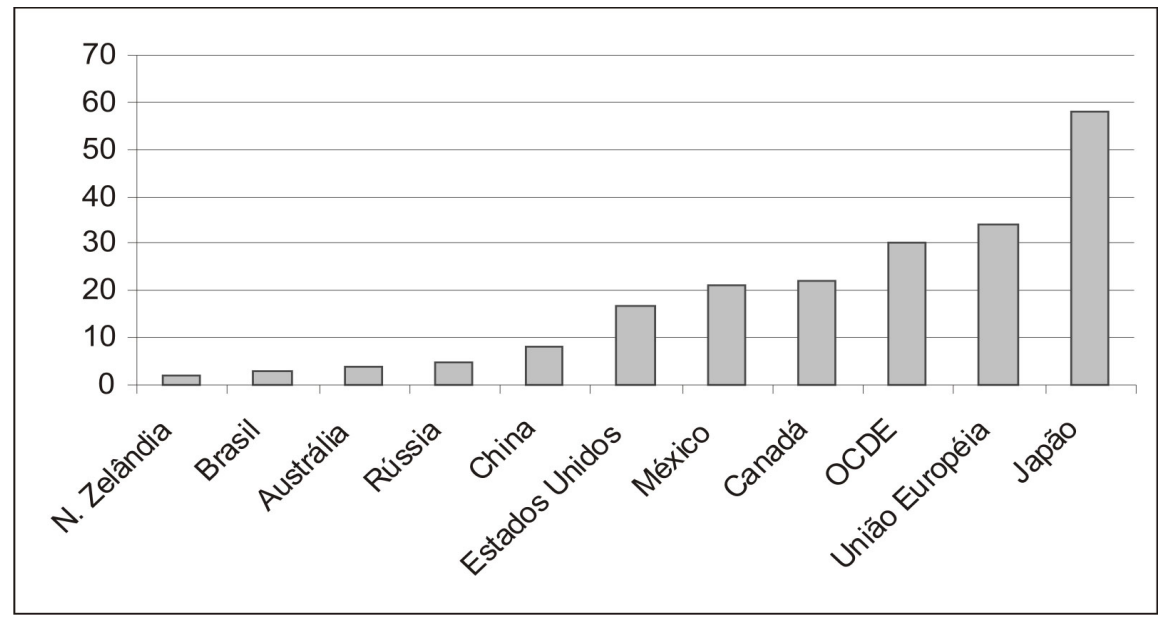

FONTE: Base de dados OCDE 2005.

NOTAS: Média de 2002-2003 para China e Rússia.

Gráfico extraído da publicação da OCDE Agricultural Policy Reform in Brazil.

No início da rodada, foi estabelecido que um texto sobre as modalidades deveria ser escrito até março de 2003, para que os países pudessem apresentar suas propostas até a Conferência de Cancun, que seria realizada em setembro daquele ano. O então presidente do Comitê Agrícola da OMC elaborou um rascunho para atender às principais posições apresentadas pelos países. No entanto, já no início da rodada os países não atingiram um consenso quanto à ambição da proposta e não puderam cumprir o prazo. Seguindo esta tendência, a V Conferência Ministerial da OMC em Cancun foi interrompida devido à falta de consenso entre os membros, principalmente no que diz respeito à agricultura. Desde o fracasso daquela reunião, a estrutura das negociações foi alterada e passou a ser conduzida separadamente por áreas.

O programa de trabalho da rodada foi finalmente aprovado em $2004 \mathrm{e}$ trouxe a estrutura a ser seguida para um eventual acordo da Rodada Doha. No que se refere à competição nas exportações, o documento traz grandes avanços, pois determina que os países devem acordar medidas para eliminar por completo os subsídios às exportações até uma determinada data. Sobre o apoio doméstico, o texto destaca prioridade para 
redução dos subsídios ao algodão e também um corte no teto de subsídios distorcivos da caixa amarela e da caixa azul, como também no de minimis, que é um valor máximo permitido para de proteção, com o qual ainda se mantém a competitividade. Já sobre o acesso a mercados, o programa de trabalho é um pouco mais vago, mencionando cortes mais profundos para tarifas que forem mais altas e flexibilização para alguns produtos mais sensíveis, que terão menores cortes tarifários (Araújo et al. 2005:60).

Em 2005, foi adotada a Declaração Ministerial de Hong Kong, segundo o qual o apoio interno à agricultura deveria ser reduzido de acordo com três faixas de proteção, em que os países com maior nível deveriam implementar maiores cortes. Além disso, foram reafirmadas a redução geral do nível de proteção, e a redução do de minimis, além da exceção para alguns dos países em desenvolvimento, que ficariam isentos destas reduções. Sobre a competição nas exportações, os membros acordaram em eliminar todas as formas de subsídios até o final de 2013, sendo que os países em desenvolvimento teriam cinco anos a mais para cumprir a determinação. No acesso a mercados, a declaração confirma que deveriam ser adotadas quatro faixas para eliminação de tarifas, além do que deveriam ser definidos os produtos considerados sensíveis. Entretanto, nenhum desses aspectos foi descrito com muita clareza (OMC, Declaração Ministerial de Hong Kong, 2005).

Após negociações que se estendiam por cinco anos, a Rodada Doha foi suspensa em 24 de julho de 2006 devido ao impasse na resolução dos temas relacionados à agricultura, apesar de concessões feitas pela União Européia e Índia relativas à agricultura (Moreira 2006). Mas quando o tema em pauta foram os subsídios domésticos norte-americanos, os representantes do país se recusaram a propor reduções, propondo compensações a possíveis perdas com a diminuição de seus subsídios através dos benefícios trazidos pelas concessões de outros países. Por isso, acusaram as propostas de outros países de serem insuficientes na abertura de mercados, para que pudessem concordar em diminuir suas proteções comerciais.

As questões técnicas que ainda permanecem pendentes para conclusão da rodada são as disciplinas por produto no contexto dos subsídios agrícolas norte-americanos, o tratamento especial para produtos sensíveis e sua relação com o acesso a mercados, além da adoção de salvaguardas e produtos especiais para países em desenvolvimento (ICONE 2006b). Portanto, a retomada das negociações em grande parte depende de um acordo entre EUA, que resistem em diminuir seus subsídios agrícolas 
RODRIGUES, T. \& PAULA, N. A agricultura nas negociações multilaterais...

com as atuais condições, o G-20 ${ }^{5}$ e o G-33 ${ }^{6}$, cujas propostas coincidem na exigência de tratamento especial aos países em desenvolvimento e de abertura dos mercados de países desenvolvidos.

Os dois grupos, apesar de serem integrados por países diferentes em tamanho, renda e competitividade no comércio, trazem um novo elemento para as negociações ao defender os interesses de países em desenvolvimento. Neste contexto, o Brasil surge como um dos países líderes, destacando-se à frente do G-20 e tendo posição decisiva principalmente nas negociações agrícolas. Isso acontece, pois o país seria um dos principais beneficiados pela abertura destes mercados. Uma estimativa da OMC afirma que a eliminação dos subsídios à exportação, que estaria prevista para 2013 caso seja alcançado um acordo, poderia trazer ganhos de US\$ 3,5 bilhões para o Brasil (Moreira 2006).

\section{Implicações da Rodada Doha para a agricultura brasileira}

As transformações do agronegócio brasileiro após meados da década de 1960 têm estado diretamente associadas com as vicissitudes dos mercados mundiais. A partir disso é possível compreender não apenas os determinantes das mudanças estruturais na base produtiva rural, mas também a capacidade de inserção das distintas atividades desse setor naqueles mercados. Segundo o Ministério da Agricultura, Pecuária e Abastecimento, entre 1998 e 2003, a taxa de crescimento do PIB do agronegócio brasileiro foi de $4,67 \%$ ao ano, causado por acesso a novas tecnologias, securitização, preços de commodities, juros pré-fixados do crédito rural, câmbio e confiança do produtor. Paralelamente, o desempenho do agronegócio no comércio mundial tem sido, ao longo das últimas décadas, surpreendente, especialmente durante o período após o plano Real, quando a balança comercial brasileira foi negativa. Enquanto o saldo da balança comercial reduziu de um superávit de US\$ 15,3 bilhões para um déficit de US\$ 6,6 bilhões, entre 1992 e 1998, o agronegócio aumentou seu superávit de US\$ 8,5 bilhões para US\$12,7

5 O G-20 é um grupo de países em desenvolvimento criado em 2003, na fase final da preparação para a V Conferência Ministerial da OMC em Cancun. Seu objetivo é abrir espaço para negociações na agricultura e defender interesses dos países em desenvolvimento. Seus membros são África do Sul, Egito, Nigéria, Tanzânia, Zimbábue, China, Filipinas, Índia, Indonésia, Paquistão, Tailândia, Argentina, Bolívia, Brasil, Chile, Cuba, Guatemala, México, Paraguai, Uruguai e Venezuela.

6 Os participantes do G-33 são Antigua e Barbuda, Barbados, Belize, Benin, Botsuana, China, Congo, Côte d'Ivoire, Cuba, República Dominicana, Granada, Guiana, Haiti, Honduras, Índia, Indonésia, Jamaica, Quênia, Coréia do Sul, Madagascar, Ilhas Mauricius, Mongólia, Moçambique, Nicarágua, Nigéria, Paquistão, Panamá, Peru, Filipinas, Saint Kitts e Nevis, Saint Lucia, Saint Vincent e Grenadines, Senegal, Sri Lanka, Suriname, Tanzânia, Trinidad e Tobago, Turquia, Uganda, Venezuela, Zâmbia e Zimbábue. O grupo reúne países preocupados com os efeitos da liberalização sobre os pequenos agricultores dos países em desenvolvimento. 
bilhões no mesmo período. Esse desempenho externo favorável do agronegócio foi mantido nos anos posteriores, especialmente após a desvalorização do Real em 1999, resultando num crescimento superior a $100 \%$ no saldo comercial de suas atividades.

Assim, embora a pauta exportadora da economia brasileira tenha apresentado uma extensa diversificação, o agronegócio continua sendo crucial na geração de renda e divisas. Esse desempenho tem sido determinado tanto por um comportamento favorável dos preços internacionais, quanto das transformações tecnológicas e produtivas que se acumularam por décadas, resultando num elevado nível de competitividade.

Segundo o Ministério da Agricultura, Pecuária e Abastecimento, em 2005, o agronegócio foi responsável por $30 \%$ do PIB brasileiro, pela geração de $37 \%$ dos empregos no país e por cerca de $40 \%$ do total de exportações. Além disso, o Brasil se destaca mundialmente nas exportações mundiais do agronegócio, sendo o primeiro país em exportações do complexo soja, açúcar, frango, café, carne bovina, suco de laranja e tabaco.

TABELA 1. PRINCIPAIS COMMODITIES EXPORTADAS PELO AGRONEGÓCIO BRASILEIRO EM US\$ BILHÕES E \%

\begin{tabular}{lcccc}
\hline \multicolumn{1}{c}{ Produto } & $\begin{array}{c}\mathbf{1 9 9 1 - 1 9 9 3} \\
\text { US\$ bi }\end{array}$ & \% & $\begin{array}{c}\mathbf{2 0 0 1 - 2 0 0 3} \\
\text { US\$ bi }\end{array}$ & $\%$ \\
\hline Soja e derivados & 2,6 & 7,4 & 6,5 & 10,2 \\
Açúcar e álcool & 0,7 & 2,0 & 2,31 & 3,6 \\
Frango & 0,5 & 1,4 & 1,51 & 2,4 \\
Café & 1,3 & 3,7 & 1,4 & 2,2 \\
Carne Bovina & 0,5 & 1,4 & 1,22 & 1,6 \\
Suco de Laranja & 0,93 & 2,6 & 1,03 & 1,6 \\
Fumo & 0,90 & 2,5 & 1 & 1,5 \\
Total & 7,4 & 21,0 & 14,9 & 23,1 \\
\hline
\end{tabular}

FONTE: Ministério do Desenvolvimento, Indústria e Comércio Exterior/SECEX e ICONE 2006a.

Por outro lado, tendo em vista que cerca de 90\% das exportações agrícolas brasileiras são representadas por commodities, e considerando o elevado grau das diversas barreiras protecionistas nos seus principais mercados, o resultado das negociações multilaterais de comércio afetará diretamente o agronegócio brasileiro (Jank et al. 2004: 22). Segundo estatísticas de maio de 2004 a abril de 2005 do Ministério da Agricultura, Pecuária e Abastecimento, os dois principais mercados para as exportações agrícolas brasileiras são a União Européia (33,3\%) e os EUA $(14,9 \%)$, que estão entre os que mais utilizam proteções à agricultura. 
RODRIGUES, T. \& PAULA, N. A agricultura nas negociações multilaterais...

Assim, a liberalização de mercados mundiais, combinada com medidas internas de melhoria de sanidade, transporte e logística, poderiam aumentar ainda mais a competitividade brasileira. Segundo Polaski (2006: 27), entre os países em desenvolvimento, o Brasil seria um dos maiores beneficiados por menor proteção no comércio agrícola mundial.

O Brasil assinou o acordo GATT na sua criação, em 1947, e se tornou membro da OMC quando esta entrou em vigor em 1 de janeiro de 1995 . O país participou de todas as negociações de comércio até hoje e teve uma posição constante a favor da diminuição de tarifas e barreiras não tarifárias sobre os produtos agrícolas e industrializados. No entanto, segundo Cruz et al. (2004), até a Rodada Uruguai, o Brasil não teve participação decisiva no fórum de negociações multilaterais e manteve uma posição low profile e defensiva. Na Rodada Uruguai, embora tenha iniciado as negociações com uma postura negativa, posteriormente se tornou mais assertivo destacando-se como um dos membros mais ativos do Grupo de Cairns, que apoiava as reivindicações norte-americanas de redução de subsídios da União Européia.

Alguns estudos da OCDE afirmam que o acordo sobre a agricultura alcançado na Rodada Uruguai não trouxe benefícios efetivos para o Brasil, já que a análise de dados demonstrou que os subsídios agrícolas dos países ricos aumentaram de US\$ 305,5 milhões na média do período-base de 1986-1988, para US\$ 345,8 bilhões na média de 2002 a 2004. O crescimento dos subsídios foi da ordem de $13,1 \%$, e pode ser atribuído à modéstia dos compromissos e à flexibilidade do monitoramento da implementação do AARU (CNA 2006).

Nas negociações da Rodada Doha, o Brasil tem tomado posição de protagonista e se firmado nos fóruns internacionais como defensor dos interesses nacionais e dos países em desenvolvimento. O país tem obtido destaque como líder do G-20, juntamente com a Índia, contribuindo ativamente para o avanço nas questões que envolvem a agricultura. A coalizão é formada por um grupo heterogêneo de países em desenvolvimento, sendo 5 países da África, 6 da Ásia e 9 da América Latina. A população dos países do G-20 representa 60\% da população mundial, $70 \%$ da população rural mundial e suas exportações equivalem a 26\% das exportações agrícolas mundiais (Jank et al. 2004:96).

O G-20 foi fundamental na elaboração do programa de trabalho da Rodada Doha, em 2004, e, desde então, consolidou sua posição como interlocutor essencial nas negociações agrícolas, reivindicando que os acordos contemplem o nível de ambição do Mandato de Doha na eliminação de barreiras ao comércio. O grupo é reconhecido por ter forte representação política nas negociações e por apresentar bom trabalho técnico na elaboração de propostas para vários itens da agen- 
da de negociações da agricultura. Segundo Chaddad \& Jank (2005), a projeção brasileira no cenário internacional e a representatividade alcançada pelo G-20 foram os maiores resultados já alcançados pelo Brasil nas negociações. No entanto, mesmo entre os países do G-20, há controvérsias principalmente no que se refere ao acesso aos mercados. Os países do Mercosul são a favor de reduções agressivas nas proteções ao comércio, embora outros países, como a China e a Índia, defendam os conceitos de Produtos Especiais e Salvaguardas Especiais aos Países em Desenvolvimento, para poderem manter tarifas e outros mecanismos de proteção que contribuam para seu desenvolvimento econômico. No entanto, no geral o G-20 tem estado de acordo com reduções mais ambiciosas nas proteções e regras menos amplas para produtos sensíveis.

As propostas defendidas pelo Brasil na Rodada Doha se baseiam no estabelecimento de negociações agrícolas amplas, não setorizadas por produtos. O país propõe a eliminação progressiva de todas as formas de subsídios, pois estes provocam queda no preço mundial dos bens agrícolas e dificultam a superação da pobreza rural nos países em desenvolvimento. No acesso a mercados, o Brasil defende a máxima diminuição das tarifas com estabelecimento de tarifas máximas permitidas ad valorem, sendo que os países em desenvolvimento devem ter tratamento diferenciado. Sobre as salvaguardas especiais, o Brasil defende a eliminação dos mecanismos que garantem salvaguardas para os produtos agrícolas, sendo o ponto principal de sua proposta a redução máxima de medidas de apoio interno em busca da liberalização dos mercados agrícolas (Barral 2002).

Além do destaque nas negociações, o Brasil obteve conquistas no fórum da OMC de resolução de disputas nos casos contra os subsídios do algodão dos Estados Unidos e do açúcar da União Européia. Estas conquistas foram muito significativas e inéditas, sendo a primeira vez que um país subdesenvolvido desafia as políticas comerciais de países desenvolvidos, por isso. No entanto, nem sempre todos os países em desenvolvimento estão a favor das iniciativas. No caso do açúcar, por exemplo, algumas antigas colônias européias produtoras de açúcar se beneficiam de acesso preferencial aos mercados europeus, portanto se opõe à posição brasileira.

O caso do algodão foi iniciado pelo Brasil em 2002, com a acusação de que os subsídios norte-americanos eram superiores aos limites estabelecidos nos compromissos com a $\mathrm{OMC}$ e que eles reduziam o preço internacional do produto, prejudicando produtores brasileiros. Segundo Chaddad \& Jank (2005: 5), os subsídios a produtores norte-americanos de algodão do período de 1998-2002 excederam o nível de 1,9 bilhões de dólares. O painel julgou que realmente os subsídios americanos cau- 
RODRIGUES, T. \& PAULA, N. A agricultura nas negociações multilaterais...

sam prejuízos ao comércio mundial com a redução de preços e que deveriam ser reduzidos. O Brasil obteve então apoio de países africanos, que solicitaram à OMC tratamento prioritário na questão do algodão, o que levou a disputa para a mídia e ampliou ainda mais o apoio ao Brasil.

No caso do açúcar, o Brasil, em conjunto com a Austrália e a Tailândia, alegou que a União Européia mantém subsídios que distorcem seriamente o mercado. Neste caso, a OMC determinou que os subsídios europeus realmente fogem às regras internacionais de comércio e que eles devem ser reduzidos, deixando mais livre um mercado de cerca de 3,8 milhões de toneladas de açúcar comercializadas anualmente (Chaddad \& Jank 2005:5). Antes mesmo da confirmação da decisão da OMC, em julho de 2004, a Comissão Européia aprovou planos de revisão de suas políticas de proteção ao açúcar, contemplando reduções modestas nos subsídios.

A expectativa do país é que na Rodada Doha seja dado prosseguimento à eliminação de subsídios a estas commodities e a outros produtos agrícolas, com um acordo para a eliminação total dos subsídios à exportação, e com reduções significativas dos subsídios domésticos distorcivos. Como já citado neste trabalho, segundo a $\mathrm{OMC}$, a eliminação dos subsídios à exportação, que estaria prevista para 2013, caso seja alcançado um acordo, poderia trazer ganhos de US\$3,5 bilhões para o Brasil (MOREIRA 2006). No entanto, caso não seja alcançado um acordo multilateral neste rodada, a prosperidade do agronegócio brasileiro estará condicionada a buscar mercados alternativos através de acordos regionais e bilaterais.

\section{Conclusões}

O objetivo da presente análise foi avaliar a evolução das negociações multilaterais ocorridas no âmbito do GATT/OMC, com ênfase na atualmente emperrada Rodada Doha. A referência inicial para tanto foi a evolução do comércio multilateral a partir da Segunda Guerra Mundial, destacando o papel do GATT e da OMC na alteração do padrão de comércio mundial, em particular no período após o início da Rodada Uruguai. O principal meio através do qual essas instituições têm agido são as negociações de comércio, em que seus países membros discutem e acordam regras que nortearão as trocas comerciais. Com isso, destaque foi dado para a trajetória das negociações envolvendo o setor agrícola, visando analisar seus efeitos na agricultura brasileira.

Desde a criação do GATT, em 1948, até o início da Rodada Uruguai, o tema agrícola ficou excluído das negociações multilaterais. Apenas a partir desta última rodada, as barreiras à agricultura foram discutidas amplamente e o acordo daí resultante não alimenta perspectivas de 
eliminação das barreiras ao comércio agrícola. Há autores que reconhecem a importância da Rodada Uruguai em trazer o setor para o centro das negociações, mas afirmam que os resultados efetivos em liberalização de comércio então alcançados são insignificantes diante do inicialmente esperado.

O estágio atual das negociações tem representado um congelamento das expectativas quanto a uma possível liberalização do comércio agrícola, tendo em vista o entrincheiramento dos países negociadores. $\mathrm{O}$ fato dos países em desenvolvimento, entre eles o Brasil, estarem participando mais ativamente das negociações tem contribuído para a formação de um ambiente mais acirrado de disputa, para além de um conflito bipolar como ocorreu na Rodada Uruguai.

Por sua vez, há claros sinais de que o Brasil será diretamente afetado pelo resultado das negociações da Rodada Doha, caso sejam concluídas. Neste caso, mesmo que os acordos sejam menos ambiciosos que o esperado, o país será beneficiado pela maior liberalização do comércio agrícola devido à elevada competitividade de sua agricultura. Por outro lado, no caso de um fracasso da rodada e da falta de um acordo, o país deverá alterar sua estratégia internacional, diminuindo a ênfase nas negociações da OMC e deslocando-se para acordos regionais e bilaterais. É importante destacar, entretanto, que com uma maior fragmentação do comércio mundial em blocos não seriam obtidos os mesmo ganhos mundiais do que com a eliminação total de subsídios num fórum multilateral de negociações.

Uma das questões que ainda permanecem abertas diz respeito à efetividade da OMC para regulação do comércio mundial. Embora se reconheça a importância da OMC para se alcançar grandes diminuições de barreiras ao comércio, sua eficácia operacional e na condução das negociações ainda é passível de questionamento. Desta maneira, mesmo que alguns acordos tenham sido alcançados no decorrer da história do GATT, eles resguardam exceções e algumas vezes não são cumpridos pela totalidade dos países, tornando-se em alguma medida inócuos. Com o vai-e-vem da Rodada Doha, estas dúvidas a respeito da OMC crescem, como se percebe na afirmação de seu diretor-geral admitindo que um fracasso na rodada poderá enfraquecer o fórum multilateral de negociações, e como tal o único mecanismo de solução de conflitos.

\section{Referências}

ACHARYA, R. \& DALY, M. (2004). "Selected Issues Concerning the Multilateral Trading System”. Discussion Paper No 7, Suíça: Organização 
RODRIGUES, T. \& PAULA, N. A agricultura nas negociações multilaterais...

Mundial do Comércio.

ARAÚJO, L. \& LIMA, R. \& JUNQUEIRA, C. (2005). “Agricultura”. In: THORSTENSEN, V. \& JANK, M. (coords.). O Brasil e os Grandes Temas do Comércio Internacional. São Paulo: Aduaneiras.

BARRAL, W. (org.) (2002). O Brasil e a OMC. Curitiba: Juruá.

BRASIL. Ministério da Agricultura, Pecuária e Abastecimento (2006). "Agronegócio Brasileiro - Propulsor do Desenvolvimento - 2005." URL: http: / / www.temasemdebate.cnpm.embrapa.br/apresentacoes / 050824_AGRONEGOCIO_elisio.ppt. Acesso: 20 de outubro de 2006.

BRASIL (2006). "Uma Oportunidade de Investimentos". URL: http:// www.portaldoagronegocio.com.br/index.php? $\mathrm{p}=$ oportunidade. Acesso: 20 de outubro de 2006.

BRASIL. SECEX (2006). "Resumo dos Mandatos de Doha”. U R L : h t t p : / / www.desenvolvimento.gov.br/sitio/secex/negInternacionais/omc/ rodDohas.php. Acesso: 16 de maio de 2006.

CARVALHO, R. \& LIMA, R. (2006). "O Impacto das Políticas Estratégicas de Comércio Exterior no Mercado Internacional de Produtos Agrícolas." Revista de Economia e Agronegócio 4 (2): 153-70.

CHADDAD, F. \& JANK, M. (2005). "Policy Coherence for Development: Issues for Brazil". In: Global Forum on Agriculture: Policy Coherence for Development, França.

CHANG, H-J. (2002). Kicking Away the Ladder: Development Strategy in Historical Perspective. Londres: Anthem Press.

CNA (Confederação da Agricultura e Pecuária do Brasil) (2006). "Frustração nas Negociações Internacionais". URL: http://www.cna.org.br/ RelatorioAtividades2005/capitulo_25/cap_25_pag01.html. Acesso: 26 de outubro de 2006.

CRUZ, S. \& SENNES, R. \& BARBOSA, A. (2004). "O Brasil no Sistema Internacional: uma Análise Retrospectiva”. In: Dimensão Global: Análise Retrospectiva. São Paulo: Instituto de Estudos Avançados da Universidade de São Paulo.

DELGADO, N. (2000). "O Regime de Bretton Woods para o Comércio Mundial: Origens, Instituições, e Significado”. Rio de Janeiro, Tese (Doutorado) Instituto de Ciências Humanas e Sociais, Universidade Federal Rural do Rio de Janeiro.

DIAKOSAVVAS, D. (2001). "The Uruguay Round Agreement on Agriculture in Practice: How Open are OECD Markets?" In: World Bank Conference: Leveraging Trade, Global Market Integration, and the New WTO Negotiations For Development, Washington D. C.

G-20 (2006). “Comunicado Ministerial do G-20”. URL: http://www.g-20.mre. gov.br/conteudo/ministerials_SP_porto1.htm. Acesso: 09 de setembro de 2006.

GILPIN, R. (2002). A Economia Política das Relações Internacionais. Brasília: Editora Universidade de Brasília. 
HOECKMAN, B. \& KOSTECKI, M. (1995). The Political Economy of the World Trading System. Oxford: Oxford University Press.

ICONE (Instituto de Estudos do Comércio e Negociações Internacionais) (2006a). "Desempenho Externo do Agronegócio Brasileiro". URL: http:// www.iconebrasil.org.br/Estatisticas/FinaisPDF/Comercio\%20agricola _site_final_04.pdf. Acesso em 16 maio de 2006.

ICONE (2006b). "Onde estão travadas as negociações da Rodada de Doha”. URL:http: / / www.iconebrasil.org.br/portugues/conteudo.asp? idCategoria $=6 \&$ idSubCategoria $=11 \&$ idDocumento $=1351 \&$ Integra $=$ Sim \&Currpage=. Acesso: 16 de maio de 2006.

JANK, M. S. \& JALES, M. (2003). “A Agricultura nas Negociações da OMC, ALCA e UE-Mercosul: Impasses e Perspectivas". In: Conferência Brasil: Desafios e Oportunidades de Integração, São Paulo.

JANK, M. S. \& NASSAR A. \& TACHINARDI, M. H. (2004). "Brasil, Potência Agrícola Mundial”. In: Cadernos Adenauer, Vol. 3 - Revolução no Campo. Rio de Janeiro: Fundação Konrad Adenauer.

MCDONALD, B. (1998). "The World Trading System: Uruguay Round and Beyond”. Londres: Macmillan.

MOREIRA, A. (2006). “Decepção e Prejuízos com a Suspensão de Doha”. Valor Econômico, São Paulo, 25 julho.

OMC \& CPA (Commonwealth Parliamentary Association) (2003). "Regional Workshops for Parliamentarians on the MultilateralTrading System". Publicação para dois workshops realizados na África do Sul e Trinidad e Tobago.

OMC (2005a). "Hong Kong Ministerial Declaration". URL: http://www.wto. org/English/thewto_e/minist_e/mino5_e/final_text_e.pdf. Acesso: 9 de outubro de 2006.

OMC (2005b). “The World Trade Organization in Brief”. URL: http:// www.wto.org/English/res_e/doload_e/inbr_e.pdf. Acesso: 31 de julho de 2006.

OMC (2005c). "Understanding the WTO". $3^{\mathrm{a}}$ ed. URL: http://www.wto.org/ English/thewto_e/whatis_e/tif_e/understanding_text_e.pdf. Acesso: 31 de julho de 2006 .

OCDE (2005). “Agricultural Policy Reform in Brazil”. URL: http://www. oecd.org/dataoecd/3/52/35543248.pdf. Acesso: 24 de maio de 2006.

POLASKI, S. (2006). "Winners and Losers: Impact of the Doha Round on Developing Countries". Washington D. C.: Carnegie Endowment for International Peace.

TUBIANA, L. (1989). "World trade in agricultural products: from global regulation to market fragmentation". In GOODMAN, D. \& M. REDCLIFT (eds). International farm crisis. Londres: Macmillan.

TREBILCOCK, M. \& HOWSE, R. (1995). The Regulation of International Trade. Londres: Routledge.

Submissão: 04 de junho de 2007

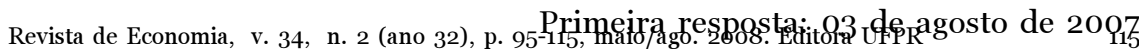
Aceite: 16 de agosto de 2007 